\title{
Comparative Study between Ringer's Lactate and Gelofusine as Preloading Infusion in Spinal Anaesthesia for Prevention of Hypotension
}

\author{
Birendra Gupta, ${ }^{1}$ Arup Ghosh, ${ }^{2}$ Amit Ray, ${ }^{3}$ Purba Haldar, ${ }^{4}$ Gautam Piplai ${ }^{5}$ \\ 'Department of Anaesthesiology, Diamond Harbour Government Medical College, Diamond Harbour, West Bengal, \\ 2Department of Anaesthesiology, Rampurhat Government Medical College, Rampurhat, Birbhum, West Bengal, \\ ${ }^{3}$ Department of General Surgery, North Bengal Medical College, Sushrut Nagar , Darjeeling, West Bengal, \\ ${ }^{4}$ Department of Anaesthesiology, Rampurhat Government Medical College,Rampurhat, Birbhum, West Bengal, \\ ${ }^{5}$ Department of Anaesthesiology and Critical Care Medicine, IPGME\&R / SSKM Hospital, Kolkata, West Bengal, India.
}

\section{ABSTRACT}

\section{Introduction}

Spinal anaesthesia is a form of safe regional anaesthetic technique but sometimes associated with few untoward side effects, most commonly hypotension. This study was planned to compare the efficacy of Ringer's lactate and Gelofusine as preloading infusion to prevent hypotension, requirement of vasopressors and requirement of total fluid given during surgery under spinal anesthrsia to maintain stable hemodynamics.

\section{Methods}

60 male patients undergoing surgery under spinal anaesthesia were randomly allocated into 2 groups. Groups were designated according to the study fluid transfused over 15 minutes as follows: Group R ( $\mathrm{n}=30$ ) - Patients receiving 10ml/kg body weight of Ringer's Lactate, Group G ( $\mathrm{n}=30$ ) Patients receiving $10 \mathrm{ml} / \mathrm{kg}$ body weight of Gelofusine. After preloading, vital parameters were recorded. Subarachnoid block was performed and Vital parameters were recorded at 1,3,5,7,9,1 $1,13,15,18,21,24,27,30,35,40,45,50,55,60,65,70,75,80,85,90$ minutes after giving subarachnoid block. All demographic and clinical parameters, level of sensory block, requirement of intraoperative Mephenteramine, intravenous fluid administration and incidence of adverse effects were documented at different points of time and compared accordingly.

\section{Results}

There was significant difference $(\mathrm{p}<0.05)$ in SBP and DBP in the two groups from 5 to 18 minutes. HR differ significantly in the groups from 7 to 18 minutes. Volume of intraoperative fluid and Mephentermine required after spinal anaesthesia is less in patients preloaded with Gelofusine as compared to Ringer's lactate.

\section{Conclusions}

Preloading with Gelofusine (colloid) is more effective than Ringer's lactate (crystalloid) in spinal anaesthesia for prevention of hypotension.

Keywords : anaesthesia; gelofusine; hypotension; preloading; ringer lactate; spinal anaesthesia.

Correspondence: Dr. Purba Haldar, Department of Anaesthesiology, Rampurhat Government Medical College, Rampurhat, Birbhum, West Bengal. Email : purbahaldar@gmail.com. Phone +91-9433474419. 


\section{INTRODUCTION}

Spinal anaesthesia is a form of safe regional anaesthetic technique but sometimes associated with few untoward side effects, mainly hypotension (incidence can be as high as 70$80 \%$ ) ${ }^{1}$, bradycardia etc due to sympathetic denervation. This hypotension is aggravated by pre operative hypovolemia which may lead to cardiovascular collapse ${ }^{2}$. Ringer's lactate is the most physiological crystalloid, its osmolality is $273 \mathrm{mosm} / \mathrm{lt}$ which is very similar to plasma - Gelatin is a colloid having $\mathrm{pH}$, osmolality similar to plasma and its plasma half life is 4-6 hrs which matches with half life of local anaesthetic (hyperbaric bupivacaine $0.5 \%$ ) used in subarachnoid block ${ }^{3}$. Various measures have been tried for prevention of hypotension ${ }^{4}$ and cardiovascular collapse ${ }^{5}$ induced by spinal anaesthesia like volume preloading ${ }^{6}$, trendelenberg position or leg elevation ${ }^{7}$ left lateral tilt in obstetric patient, leg compression by compression inflatable splint, prophylactic use of vasopressors ${ }^{8 .}$ All measures have their own limitations. Fluid loading studies have assessed the optimal type of fluid ( crystalloid compared with colloid solution) and the timing of administration ( given before spinal anesthesia - preloading, or given immediately after spinal block placement - coloading ) as rapid infusion. This study was planned to compare the efficacy of ringer's lactate and gelofusine as preloading infusion to prevent hypotension and bradycardia. The level of sensory block, requirement of vasopressors , total fluid given during surgery to maintain stable hemodynamics and incidence of adverse events were also compared.

\section{METHODS}

Institutional ethical committee clearance and written informed consent were obtained before this prospective, observational study from 60 male patients undergoing elective herniotomy ,herniorraphy or hernioplasty under spinal anaesthesia belonging to age group 18 to 55 years, height between 150-160 cm, ASA physical status I and II and baseline Systolic blood pressure 110-130 mm Hg. Patients having any contraindication for neuraxial block were excluded from the study. Preoperatively, all patients undergone through physical and systemic examinations along with all necessary laboratory investigations. Patients were advised to take tab Ranitidine $150 \mathrm{mg}$ before light meal and tab Alprazolam $0.25 \mathrm{mg}$ before going to bed on day before surgery . On the day of surgery, Routine monitors were attached and pre-loading parameters (HR,SBP,DBP,MAP) were documented and patients were randomly allocated into 2 groups of 30 patients each using a computer generated random table. Groups were designated according to the study fluid transfused over 15 minutes as follows: Group R $(\mathrm{n}=30)$ - Patients receiving $10 \mathrm{ml} / \mathrm{kg}$ body weight of Ringer's Lactate, Group G ( $n=30)$ - Patients receiving $10 \mathrm{ml} / \mathrm{kg}$ body weight of Gelofusine. The subarachnoid block was administered with a 26 G Quincke's spinocan needle at L3L4 intervertebral space with $2.75 \mathrm{ml}$ of $0.5 \%$ inj. hyperbaric bupivacaine $+0.5 \mathrm{ml}(25 \mu \mathrm{gm})$ of inj. Fentanyl. Patients were placed in supine position immediately. Arterial pressure and heart rate were measured at 2 mins interval beginning $1 \mathrm{~min}$ after the spinal injection for first 15 mins, then every 3 mins interval for next 15 mins and lastly every 5 mins interval for next 60 mins. Ringer's lactate was infused at rate of 15 $\mathrm{ml} / \mathrm{kg} /$ hour considering fluid deficit correction, maintenance fluid and third space loss to all patient. When SBP falls below $20 \%$ of its baseline, it was considered as significant hypotension. Fall in MAP of $\leq 65 \mathrm{~mm} \mathrm{Hg}$ was managed with inj. Mephentermine $6 \mathrm{mg}$ i.v. bolus and rapid infusion of $250 \mathrm{ml}$ of Ringer's lactate to maintain SBP in target range of $\pm 10 \%$ of baseline SBP. 10 
minutes after spinal injection, the sensory block level was determined by touching the skin with cotton moistened with spirit for perception in difference of thermal sensations and preparation for surgery was started. Bradycardia was defined as heart rate $<60 / \mathrm{min}$ and was treated with inj. Atropine $0.6 \mathrm{mg}$ i.v. Nausea and vomiting was treated with inj. Ondansetron 4mg. shivering patient was managed with inj. Tramadol 25 mg. During the course of study, if any patient suffered from any surgical complications like severe bleeding or needed re-exploration or needed to be converted into general anaesthesia, then these cases were excluded from our study. All demographic parameters (Age, Body weight, Height), clinical parameters ( Heart Rate, Systolic Blood Pressure, Diastolic Blood Pressure, Mean Arterial Pressure, level of Sensory block, intraoperative Mephentermine administeramine, introperative I.V. fluids given and incidence of adverse effects (Hypotension, Bradycardia, arrhythmia, nausea vomiting and allergic reaction) were documented.

\section{STATISTICAL ANALYSIS}

Sample size have been calculated using the formula $\mathrm{n}>2(\mathrm{Z} \alpha+\mathrm{Z} 1-\beta) 2 \times \mathrm{p}^{*} \mathrm{q} / \mathrm{d} 2$, where $\mathrm{p}=(\mathrm{p} 1+\mathrm{p} 2) / 2, \mathrm{q}=1-\mathrm{p}$, and $\mathrm{d}$ is $\mathrm{p} 1-\mathrm{p} 2$. Now assuming $\mathrm{p}$ value $<0.05$ to be significant and considering effect to be two sided, we get $\mathrm{Z} \alpha$ $=1.96$; assuming power of study to be $90 \%$ we get $\mathrm{Z} 1-\beta=1.28$. taking $\mathrm{p} 1$ and $\mathrm{p} 2$ as the percentage of hypotension in the two groups as $50 \%$ and $10 \%$ respectively using the above formula we get $\mathrm{n}=$ 23 in each group. Hence minimum 23 samples are required in each group. For convenience 30 patients has been taken in each group. So, total sample size is $30+30=60$.

Categorical variables will be expressed as number of patients and percentage of patients and compared across the two groups using Pearson's ChiSquare test for independence of attributes. Continuous variables will be expressed as Mean \pm standard deviation and compared across the two groups using unpaired $\mathrm{T}$ test if the data follows normal distribution and Mann Whitney U test if the data does not follow normal distribution. The statistical software SPSS version 20 will be used for the analysis. An alpha level of $5 \%$ has been taken, i.e. if any $p$ value is less than 0.05 , it will be considered as significant.

\section{RESULTS}

Comparison of the demographic parameters (Age, weight, height, BMI and ASA physical status) of the patients in the two groups showed that there was no significant difference in demographic parameters of the patients when compared in both groups. Table 1 describes that there was no significant difference in vital parameters before and after loading of i.v. fluids in patients.

Table 1. Comparison of different vital parameters before and after loading of i.v. fluid in the patients.

\begin{tabular}{|l|c|c|c|}
\hline \multicolumn{1}{|c|}{$\begin{array}{c}\text { Vital } \\
\text { parameters }\end{array}$} & $\begin{array}{c}\text { PRE-LOADING } \\
\text { (Mean } \pm \text { SD) }\end{array}$ & $\begin{array}{c}\text { AFTER } \\
\text { LOADING } \\
\text { (Mean } \pm \text { SD) }\end{array}$ & $\begin{array}{c}\text { P } \\
\text { Value }\end{array}$ \\
\hline Heart Rate/min & $83.72 \pm 4.87$ & $83.77 \pm 4.85$ & 0.182 \\
\hline $\begin{array}{l}\text { Systolic Blood } \\
\text { Pressure (mm } \\
\text { Hg) }\end{array}$ & $121.35 \pm 4.07$ & $121.40 \pm 4.10$ & 0.083 \\
\hline $\begin{array}{l}\text { Diastolic Blood } \\
\text { Pressure (mm } \\
\text { Hg) }\end{array}$ & $79.80 \pm 3.89$ & $79.87 \pm 3.90$ & 0.103 \\
\hline $\begin{array}{l}\text { Mean Arterial } \\
\text { Pressure (mm } \\
\text { Hg) }\end{array}$ & $93.62 \pm 3.49$ & $93.67 \pm 3.48$ & 0.083 \\
\hline
\end{tabular}

After giving subarachnoid block, there was fall in systolic blood pressure in both groups. SBP in Group- $R$ decreases to a minimum at 13 minutes, after that it begin to rise while in Group-G, SBP decreases to a minimum at 21 minutes, after that it increases till end. There was a significant 
difference in SBP in the two groups from 5 to 18 minutes with greater fall in SBP in Group-R as compared to Group-G.

After giving subarachnoid block, there was fall in diastolic blood pressure in both groups. DBP in Group-R decreases to a minimum at 13 minutes, after that it begin to rise while in Group-G, DBP decreases to a minimum at 21 minutes, after that it increases till end. There was a significant difference in DBP in both groups from 5 to 18 minutes with greater fall in DBP in Group-R as compared to Group-G.

Table 2 : Comparison of Mean Arterial Pressure (MAP) in both groups at different time interval intraoperatively.

\begin{tabular}{|c|c|c|c|}
\hline $\begin{array}{c}\text { TIME } \\
\text { (mins) }\end{array}$ & $\begin{array}{c}\text { GROUP -R } \\
\text { (Mean } \pm \text { SD) }\end{array}$ & $\begin{array}{c}\text { GROUP - G } \\
\text { (Mean } \pm \text { SD) }\end{array}$ & p value \\
\hline 1 & $92.50 \pm 3.79$ & $93.67 \pm 3.28$ & 0.208 \\
\hline 3 & $90.50 \pm 3.99$ & $92.57 \pm 3.23$ & 0.031 \\
\hline 5 & $88.07 \pm 3.88$ & $91.60 \pm 3.10$ & 0.000 \\
\hline 7 & $84.80 \pm 4.53$ & $90.60 \pm 3.41$ & 0.000 \\
\hline 9 & $79.70 \pm 5.52$ & $89.47 \pm 3.14$ & 0.000 \\
\hline 11 & $75.03 \pm 6.40$ & $88.40 \pm 3.38$ & 0.000 \\
\hline 13 & $72.03 \pm 7.27$ & $87.47 \pm 3.19$ & 0.000 \\
\hline 15 & $73.77 \pm 5.18$ & $86.53 \pm 3.45$ & 0.000 \\
\hline 18 & $77.17 \pm 5.23$ & $83.23 \pm 4.96$ & 0.000 \\
\hline 21 & $80.50 \pm 4.52$ & $81.30 \pm 6.12$ & 0.569 \\
\hline 24 & $80.87 \pm 4.06$ & $81.60 \pm 7.57$ & 0.642 \\
\hline 27 & $81.07 \pm 3.90$ & $81.53 \pm 9.34$ & 0.801 \\
\hline 30 & $81.60 \pm 3.93$ & $83.70 \pm 7.46$ & 0.178 \\
\hline 35 & $83.43 \pm 4.49$ & $84.70 \pm 4.76$ & 0.293 \\
\hline 40 & $84.47 \pm 3.94$ & $85.53 \pm 3.47$ & 0.270 \\
\hline 45 & $85.67 \pm 3.88$ & $87.30 \pm 3.08$ & 0.076 \\
\hline 50 & $88.10 \pm 3.77$ & $89.20 \pm 3.02$ & 0.218 \\
\hline 55 & $88.80 \pm 3.52$ & $90.03 \pm 2.92$ & 0.145 \\
\hline
\end{tabular}

\begin{tabular}{|l|l|l|l|}
\hline 60 & $90.77 \pm 3.18$ & $92.03 \pm 2.70$ & 0.102 \\
\hline 65 & $91.50 \pm 2.87$ & $92.77 \pm 2.37$ & 0.068 \\
\hline 70 & $92.60 \pm 2.82$ & $93.43 \pm 2.40$ & 0.223 \\
\hline 75 & $92.93 \pm 2.53$ & $94.20 \pm 2.50$ & 0.056 \\
\hline 80 & $93.57 \pm 2.87$ & $94.43 \pm 2.75$ & 0.238 \\
\hline 85 & $93.53 \pm 2.76$ & $94.73 \pm 2.52$ & 0.084 \\
\hline 90 & $94.00 \pm 2.57$ & $95.10 \pm 2.26$ & 0.084 \\
\hline
\end{tabular}

Table 2 shows that after giving subarachnoid block, there was fall in mean arterial pressure in both groups. MAP in Group-R decreases to a minimum at 13 minutes, after that it begin to rise while in Group-G, MAP decreases to a minimum at 27 minutes, after that it increases till end. There was a significant difference in MAP in both groups from 3 to 18 minutes with greater fall in MAP in Group-R as compared to Group-G.

Figure 1 shows that after giving subarachnoid block, there was fall in heart rate in both groups. $\mathrm{HR}$ in Group-R decreases to a minimum at 13 minutes, after that it begin to rise while in Group-G, HR decreases to a minimum at 21 minutes, after that it increases till end. There was a significant difference in HR in both groups from 7 to 18 minutes with greater fall in HR in Group-R as compared to Group-G.

Table 3. Number of patients requiring Mephentermine to treat hypotension in both groups $(n=60)$.

\begin{tabular}{|l|l|l|l|l|}
\hline & \multicolumn{3}{|c|}{ MEPHENTERMINE } & \\
\cline { 1 - 4 } & REQUIRED & $\begin{array}{c}\text { NOT } \\
\text { REQUIRED }\end{array}$ & TOTAL & \multirow{2}{*}{$\begin{array}{c}\text { p value } \\
0.032\end{array}$} \\
\cline { 1 - 4 } GROUP-R & $15(50 \%)$ & $15(50 \%)$ & $30(100 \%)$ & \\
\hline GROUP-G & $7(23.3 \%)$ & $23(76.7 \%)$ & $30(100 \%)$ & \\
\hline
\end{tabular}

Pearson Chi-Square value $=4.593 . \mathrm{df}=1$

Table 3 shows that 15 (50\%) patients required Mephentermine in Group- $\mathrm{R}$ in comparision to $7(23.33 \%)$ patients in Group-G indicating significant difference in two groups. 


\begin{tabular}{|c|c|c|c|}
\hline & $\begin{array}{l}\text { GROUP - R } \\
\text { (Mean } \pm \text { SD) }\end{array}$ & $\begin{array}{l}\text { GROUP - G } \\
\text { (Mean } \pm \text { SD) }\end{array}$ & \multirow{2}{*}{$\begin{array}{l}\text { P value } \\
=0.069\end{array}$} \\
\hline $\begin{array}{r}\text { I.V. FLUID } \\
(\mathrm{ml})\end{array}$ & $1385.00 \pm 148.64$ & $1321.67 \pm 114.23$ & \\
\hline
\end{tabular}

Table 4 shows that mean amount of fluid required for each patient in Group- $\mathrm{R}$ is more than that of Group-G but the difference is not significant.

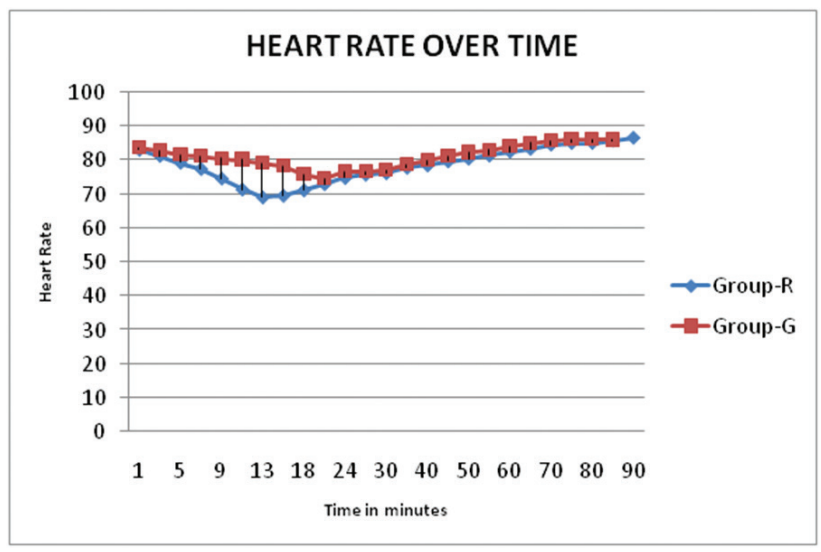

Figure 1. Heart rate at different time interval in both groups intraoperatively

The level of sensory block achieved were comparable in the patients in both groups. Comparison of incidence of adverse effects intraoperatively in both groups $(n=60)$. showed bthat out of 30 patients in each group, incidence of adverse effects were $9(30 \%)$ in Group-R and 4 (13.3\%) in Group-G but there was no significant difference. 7 patients had nausea and vomiting in Group-R as compared to 4 patients in Group-G. 2 patients had rigor in both groups. While none of the patients had bradycardia, anaphylaxis or arrhythmias.

\section{DISCUSSION}

Hypotension continues to be the most common and most dreaded complication of spinal anaesthesia specially in case of pregnant mothers and elderly patients. This hypotension is aggravated by preoperative hypovolemia which may lead to cardiovascular collapse ${ }^{4}$ and even death. Traditionally fluid loading regimens are considered as the main method as prophylaxis against hypotension, where vasopressors were more commonly considered for the treatment of hypotension. Different crystalloids and colloids have been used as preloading fluid for prevention of hypotension induced by spinal anesthesia. Crystalloids commonly used in preloading are Ringer's Lactate and normal saline. Colloids that are used in preloading are Gelatin, Dextran Hetastarch, Pentastarch and Tetrastarch. Preloading, intravenous fluid transfused before anaesthesia, was first described by Wollman and Marx. ${ }^{9}$ offset the vasodilating effects of sympathetectomy maintaining the venous return. Co-loading seems to be more appropriate physiologically as the increase in intravascular volume brought about by co-loading coincides with the time of maximal vasodilatation effect of spinal anaesthesia ${ }^{10}$. Adverse effect of coloading include decreased oxygen carrying capacity and increased risk of pulmonary oedema on pregnant patients ${ }^{11}$. Approximately $75 \%$ of any crystalloid diffuses into interstitial space and large volume of crystalloid may be harmful in patients with congestive cardiac failure and renal impairment which can lead to peripheral and pulmonary oedema with little effect on plasma volume ${ }^{12}$. Recent studies shows that the prophylactic administration of colloids (Gelofusine) may be more effective than crystalloid preloading ${ }^{13}$. Being large molecules, they are retained into the vascular space unlike crystalloids. The measured initial volume effect of Gelofusine is about $100 \%$ of the infused. The solution also restores the extravascular compartment, does not disturb the electrolyte balance of the extracellular space. So they are about three times more potent than crystalloids for increasing vascular volume and supporting cardiac output ${ }^{14}$. However, prophylactic administration of colloids are not popular 
routinely due to increased cost, possibility of derangement of coagulation, suppression of platelet activity and risk of anaphylaxis. Rout CC, Akoojee SS, Rocke DA, Gouws E (1992) 15 demonstrated that rapid administration of crystalloid preload before spinal anaesthesia in caesarean section did not decrease the incidence or severity of hypotension, and questioned the role of crystalloid preload. Olthof CG, de Vries JP et al. (1993) ${ }^{16}$ in their study concluded that infusion of 0.8 litre of gelatin results in a larger and longer lasting increase in blood volume than 2 litres of Ringer's lactate, probably due to mobilization of extracellular fluid volume. Dureja GP, Ghai B, Prakash S(2001) ${ }^{17}$ conducted a study in 110 ASA 1 patients and concluded that preloading with Gelofusine is safe and an effective measure to decrease the intensity and severity of hypotension during induction of spinal anaesthesia as compared to ringer lactate. Ngan Kee WD, Khaw Knotzer H, Pajk W , Maier S et al (2006) ${ }^{18}$ in their study "Comparison of lactated Ringer's, gelatine and blood resuscitation on intestinal oxygen supply and mucosal tissue oxygen tension in haemorrhagic shock" concluded that Blood or gelatine infusion improves mucosal tissue oxygenation of the porcine jejunum after severe haemorrhage when compared with lactated Ringer's solution. Arora P, Singh R.M, Kundra $S$ et.al. (2015) ${ }^{19}$ in their study on 90 term parturients concluded that Colloid preloading and co-loading are equally effective and both are superior to crystalloid preloading for prevention of maternal hypotension.

In our study we compared the intraoperative vital parameters between the two groups, Group $\mathrm{R}$ who received Ringer's lactate and Group $G$ who received Gelofusine as preloading infusion before spinal anaesthesia. There was progressive fall in all the vital parameters in both groups after spinal anaesthesia with SBP,
DBP and HR minimum at 13 minutes in Group $\mathrm{R}$ and minimum at 21 minutes in Group $\mathrm{G}$ after giving spinal anaesthesia. There was significant difference in SBP and DBP in the two groups from 5 to 18 minutes. HR differs significantly in the groups from 7 to 18 minutes and MAP differs significantly from 3 to 18 minutes in both groups. Overall decrease in vital parameters were more in Group R as compared to Group G.

These results were similar to the findings reported by Jalandhara B, Makwana JC ${ }^{20}$ in their studies they concluded that there was significant hypotension with crystalloid group intraoperatively inspite of preloading and also intraoperatively fluid requirement was high as compared to colloid group. Similar observations were made by Dahlegren $G$ et al ${ }^{21}$ and Singh B et al ${ }^{22}$ where they found colloid (Dextran and $6 \%$ HES respectively) preloading to be more effective in preventing hypotension as compared to crystalloid(Ringer lactate) preloading. The more stable hemodynamic status observed after colloid administration relates to the fact that colloid solution is retained in intravascular compartment for longer time than crystalloids.

There are few limitations of our study. We didn't include control group ( without preloading) to compare our study groups and our study was single blinded. We included only ASA grade I and grade II patients without any comorbidities. Patients with cardiovascular instability, renal or liver dysfunction, $\mathrm{BMI}>25 \mathrm{KG} / \mathrm{m}^{2}$, ASA grade III \& grade IV WERE EXCLUDED FROM OUR STUDY. Future studies are to be conducted to find out the effect of preloading with colloid and crystalloid in these high risk patients, pregnant mothers and patients with comorbidities to prevent the spinal hypotension.

\section{CONCLUSION}

Incidence of hypotension, bradycardia, nausea and vomiting, amount of intraoperative fluid 
and Mephentermine required after spinal anaesthesia is less in patients preloaded with Gelofusine as compared to Ringer's lactate. Our conclusion from the study is that preloading with Gelofusine (colloid) is more effective than Ringer's lactate (crystalloid) in spinal anaesthesia for prevention of hypotension.

\section{REFERENCES}

1. Mercier FJ, Auge M, Hoffmann C, Fischer C, Le Gouez A. Maternal hypotension during spinal anesthesia for caesarean delivery. Minerva Anestesiol 2013;79:6273.

2. Auroy Y, Benhamou D, Bargues L: Major complications of regional anaesthesia in France: The SOS Regional Anaesthesia Hotline Service. Anesthesiology 2002;97:1274-80.

3. Cardoso MMSC, Bliacheriene S, Freitas CRC, Cesar DS, Torres MLA. Preload during spinal anesthesia for cesarean section. Comparision between crystalloid and colloid solutions. Revista Brasileira de Anestesiologia 2004 Nov/Dec;54:6.

4. Butwick AJ, Columb MO, Carvalho B. Preventing spinal hypotension during caesarean delivery: what is the latest? BJA 2015 Feb 1;114:183-186.

5. Chooi C, Cox JJ, Lumb RS, Middleton P, Chemali M, Emmett RS, Simmons SW, Cyna AM. Techniques for preventing hypotension during spinal anaesthesia for caesarean section. Cochrane Database of Systematic Reviews 2017; CD002251.

6 Mercier FJ. Fluid loading for caesarean delivery under spinal anesthesia: have we studied all the options?. Anesth Analig 2011;113:677-80.

\section{ACKNOWLEDGEMENTS}

The authors would like to thank all the patients in the study, entire department of Anaesthesiology \& Surgery, and all supporting staffs.

7 Hasina A, Aiyad A, Elsakka A, et al. Leg elevation decreases the incidence of postspinal hypotension in cesarean section: a randomized controlled trial. BMC Anesthesiology. 2017 Apr 24; Available at https://doi.org/10.1186/s12871-017-03498 .

8. Loubert C. Fluid and vasopressor management for Cesarean delivery under spinal anesthesia: continuing professional development. Can J Anaesth 2012;59:604-19.

9. Wollman S, Marx C. Acute hydration for prevention of hypotension of spinal anesthesia in parturients. Anesthesiology. 1968;29:374-80.

10. Dyer RA, Farina Z, Joubert IA, Du Toit $P$, MeyerM, Torr G, etal.Crystalloid pre-load versus rapid crystalloid administration after induction of anaesthesia (coload) for elective caesarean section. Anaesth Intensive Care. 2004;32:351-7.

11. MacLennan FM, MacDonald AF, Campbell DM. Lung water during the puerperium. Anaesthesia. 1987;42:141-7.

12. Williams EL, Hildebrand KL, McCormick SA, Bedel MJ. "The effect of intravenous lactated Ringer's solution versus $0.9 \%$ sodium chloride solution on serum osmolality in human volunteers". Anesth. Analg 1999 May; 88 (5): 999-1003. 
13. Mc Donald S, Fernando R, Ashpole K, Columb M. Maternal cardiac output changes after crystalloid or colloid following spinal anesthesia for elective cesarean delivery:a randomized controlled trial. Anesth Analog 2011;113:803-10.

14. Pandya S. Practical Guidelines on Fluid Therapy. India. Pandya S 2008;2:37.

15. Rout CC, Akoojee SS, Rocke DA, Gouws E. Rapid administration of crystalloid preload does not decrease the incidence of hypotension after spinal anaesthesia for elective caesarean section. Br J Anaesth. 1992 Apr;68(4):394-7.

16. Olthof CG, de Vries JP, de Vries PM, Kouw PM, Donker AJ, de Lange JJ. The influence of Ringer's lactate and gelatin infusion on the internal fluid balance of healthy volunteers measured by a noninvasive conductivity technique. Eur J Anaesthesiol. 1993 Nov;10(6) : 397-402.

17. Dureja GP, Ghai B, prakah S. Comparative evaluation of Ringer lactate and Gelofusine solution as preloading fluid, for prevention of Hypotension following spinal anaesthesia. Hospital today 2001; VI(10): 629- 31.
18. Knotzer H, Pajk W, Maier $S$ et al. Comparison of lactated Ringer's, gelatine and blood resuscitation on intestinal oxygen supply and mucosal tissue oxygen tension in haemorrhagic shock. BJA 2006 Oct;97(4):509-16.

19. Arora P, Singh RM, Kundra S, Gautam PL. Fluid Administration Before Caesarean Delivery:Does Type and Timing Matter? JCDR 2015 June;9(6):UC 01-04.

20. JalandharaB,Makwana JC.AComparative Study of Crystalloid and Colloids as Preloading in Spinal Anaesthesia for Prevention of Hypotension. GSMC J Med Sci 2014 Jan-June;vol(III) no. (I).

21. Dahlgren G, Granath F Pregner K et al. Colloid vs crystalloid preloading to prevent maternal hypotension during spinal anesthesia for elective cesarean section. Acta Anaesthesiol Scand. 2005, 49(8):1200-6.

22. Singh B, Singh AP, Bhardwaj A, Singh I. Comparative study of Preloading with Ringer Lactate V/S 6\% Hexa Starch Solutions to Prevent Hypotension Following Spinal Anaesthesia in Elective Surgery. Int Jour Med Den Sci 2016 July;5(2).

Citation: Gupta B, Ghosh A, Ray A, Haldar P, Piplai G. A Comparative Study Between Ringer's Lactate and Gelofusine as Preloading Infusion in Spinal Anaesthesia for Prevention of Hypotension. JCMS Nepal. 2021 ; $17(4) ; 360-67$. 